Hydrol. Earth Syst. Sci., 10, 889-902, 2006

www.hydrol-earth-syst-sci.net/10/889/2006/

(C) Author(s) 2006. This work is licensed

under a Creative Commons License.

\title{
Uncertainty in soil physical data at river basin scale - a review
}

\author{
P. van der Keur ${ }^{1}$ and B. V. Iversen ${ }^{2}$ \\ ${ }^{1}$ Geological Survey of Denmark and Greenland, Østervoldgade 10, 1350 Copenhagen K, Denmark \\ ${ }^{2}$ Danish Institute of Agricultural Sciences, P.O. Box 50, 8830 Tjele, Denmark
}

Received: 4 April 2006 - Published in Hydrol. Earth Syst. Sci. Discuss.: 6 July 2006

Revised: 20 October 2006 - Accepted: 10 November 2006 - Published: 22 November 2006

\begin{abstract}
For hydrological modelling studies at the river basin scale, decision makers need guidance in assessing the implications of uncertain data used by modellers as an input to modelling tools. Simulated solute transport through the unsaturated zone is associated with uncertainty due to spatial variability of soil hydraulic properties and derived hydraulic model parameters. In general for modelling studies at the river basin scale spatially available data at various scales must be aggregated to an appropriate scale. Estimating soil properties at unsampled points by means of geostatistical techniques require reliable information on the spatial structure of soil data. In this paper this information is assessed by reviewing current developments in the field of soil physical data uncertainty and adopting a classification system. Then spatial variability and structure is inspected by reviewing experimental work on determining spatial length scales for soil physical (and soil chemical) data. Available literature on spatial length scales for soil physical- and chemical properties is reviewed and their use in facilitating change of spatial support discussed. Uncertainty associated to the derivation of hydraulic properties from soil physical properties in this context is also discussed.
\end{abstract}

\section{Introduction}

The scope of this paper is on the issue of providing guidance on classification and quantification of uncertainty associated with soil physical- and chemical data in the unsaturated zone at the river basin scale. The underlying idea for the present paper is inspired by the need for providing guidance for the assessment of uncertain soil data targeted towards practitioners within hydrological modelling. For performing environmental hydrological modelling studies for assessing implications of politically imposed measures for the reduction of environmental pollution there is a need for decisionmakers to evaluate the results of modelling studies against the background of uncertain data input needed for a comprehensive assessment of the effect of measures and associated costs. Questions posed by decision-makers regarding how confident they can be about simulated measures having implications for cost-effectiveness are most relevant. This has called for research relevant policy-making and integrating social and physical perspectives on environmental problems, that traverse a range of political and geographic scales (Brown and Heuvelink, 2005). Outcomes of environmental modelling studies are never certain due to uncertainty in model parameterization, boundary conditions of the model and also due to uncertainty in the model itself. The latter uncertainty arises from the fact that the hydrological model always is a more or less crude simplification of the reality in nature. Represented soil processes in the model do only capture real processes approximately. In this paper a model is defined as a numerical code that is imposed on an interpretation of the environmental system, which processes it mimics. The representation of the environmental system itself is also often called a model in literature, but in the context of the present paper the model that is representing the environmental system is denoted a conceptual model. For instance, parameterization of a groundwater model requires a correctly interpreted geological model. In this case the groundwater model is the numerical model, e.g. MODFLOW, and the interpreted geological model is the conceptual model (Refsgaard et al., 2006). Focus here is thus on making transparent to user groups the uncertainty related to spatial soil physical data at the river basin scale required for the parameterization of a model for environmental hydrological studies.

Correspondence to: $\mathrm{P}$. van der Keur

(pke@geus.dk)

Published by Copernicus GmbH on behalf of the European Geosciences Union. 


\section{Soil physical and chemical properties in the vadose zone}

The soil system represented by soil physical properties is a very complex system and result from physical, chemical and biological processes over time. The soil has been recognized as a key compartment in biochemical cycles (carbon, nitrogen, water, etc.) and underlying physico-chemical processes are still only partly understood and subject of research (Gratwohl et al., 2004). The variation of the soil system is in fact so complex that no description of it can be complete and so prediction is inevitably uncertain (Heuvelink and Webster, 2001). Soil properties can vary over time as a result of impact by climate and land management. However, in this paper only spatial variation is considered over the time scale relevant for environmental assessments within e.g. the EU Water Framework Directive (WFD), i.e. a few decades. One of the major causes for uncertainty and erroneous understanding of causal relationships and the magnitude of parameters and trends has been identified as the scale problem. Different levels of heterogeneity are encountered when passing from the microscopic to the macroscopic scale. Processes identified and regarded valid at one scale may not hold at another spatial scale. At the field scale, the modelling of nitrate leaching may focus on the influence of natural variation in the soil, but at the larger farm scale the variation in landuse will be much more important (Heuvelink and Pebesma, 1999). This scaling issue remains one of the largest problems in soil science and hydrology and various techniques have been developed to scale soil physical properties (refer to Pachepsky et al. (2003) for a comprehensive review). In soil physics, the description of water flow in soils is based on gradients in soil water potential, which in soils is predominantly determined by capillary and gravitational forces. This concept has been applied and thoroughly tested at the scale of a soil column. Predictions of water flow at larger scales are therefore an extrapolation based on the assumption that the hydraulic properties of the soil, determined at the local scale, may represent the properties at a larger scale.

In this paper soil physical data is closely linked to soil hydraulic properties, like water retention data and hydraulic conductivity. Soil hydraulic properties can be derived from basic soil physical properties like texture from general purpose soil maps using pedotransfer functions (PTFs; Bouma, 1989; Børgesen and Schaap, 2005; Rawls et al., 1982; Wösten et al., 1999; Pachepsky et al., 1996, 2006) and are needed for parameterization of hydrological models used to describe water- and solute transport through the vadose zone. Soil hydraulic properties may also be measured directly from samples in the laboratory and the soil hydraulic conductivity may be determined in-situ in the field (e.g. Mohanty et al., 1994; Severino et al., 2003), but this procedure is often cumbersome and expensive and therefore not feasible in practice at the scale of the river basin. The water flow direction in the vadose zone is often assumed to be vertical only. Vogel and
Roth (2002) provide a review of flow and transport in the unsaturated domain at various spatial and temporal scales and also covering modelling aspects. The groundwater zone is the saturated domain and water- and solute transport may be represented in 3-D. Therefore, model simulated flow is dependent on knowledge of the geological structure to ensure a realistic conceptual model of the system at hand. Uncertainty related to parameterization of groundwater models is dealt with elsewhere (Nilsson et al., 2006).

Environmental risk assessment in which an evaluation of the uncertainty associated with pollutant fate modelling for decision making within a hydrological context are currently receiving a vast amount of interest (see e.g. Dubus et al., 2003 , for a review on uncertainty associated with pesticide fate modelling, and e.g. Worrall et al., 2002, and Søvik et al., 2003 , for a review on uncertainty in a more general geochemical context). Quinn et al. (2004) argues that the modeller must use the appropriate type of model at the appropriate scale for modelling of nitrate leaching in order to best understand nitrate losses at that scale and appreciate associated uncertainty. One of the primary contributors to the uncertainty in contaminant concentration predictions is uncertainty in the hydraulic parameters of soils at a site (e.g. Meyer et al., 1999), but geochemical properties, like CEC and $\mathrm{pH}$, also play an important role (Grathwohl et al., 2003, 2004). Sensitivity analyses with the Danish DAISY model (Hansen et al., 1991) showed that nitrate variations in soil texture substantially affects nitrate leaching (Watertech, 2005). The amount of organic matter in the soil affects both hydraulic properties and mineralization. Organic pollutants (e.g. pesticides) are characterised by compound specific properties such as sorption and degradation and heavily dependent on both the soil physical and the soil chemical environment. Refer to Wauchope et al. (2002) for a review on pesticide soil sorption parameters, Delle Site (2000) for a review on factors affecting sorption of organic compounds in water systems for selected pollutants, and Beulke et al. (2000) for a review on simulation of pesticides on the basis of laboratory data. Geochemical and biological processes are predominant factors of the fate and transport of contaminants in soils and the unsaturated zone. Often these processes are studied separately. Detailed modelling approaches have been developed to couple the description of water flow and geochemical interactions as well as microbiological processes. They are functionally strongly related, where small-scale heterogeneity serves as an important factor to provide a niche for surviving organisms (Grathwohl et al., 2004). Leaching of contaminants through the soil is controlled by many environmental parameters and their effect on contaminant release is to a very large extend compound specific. E.g., leaching of heavy metals is heavily dependent on $\mathrm{pH}$, presence of dissolved organic carbon and changes in redox potential (van der Sloot et al., 2004). Heavy metals and other toxic elements are thus subject to a complex speciation in the unsaturated zone. The conceptual approach of interface interaction between solid 
compounds (including complex minerals and natural organic matter) is well developed, but the validation of the different concepts and the quantification of related parameters is still uncertain and subject to scientific discussion (Grathwohl et al., 2004). Volatile compounds (VOCs) leach to groundwater unless biodegraded by micro-organisms which in turn depend on other geochemical conditions for their existence. Other compounds such as various complex organic mixtures are also biodegradable, but may be very persistent over many decades to centuries. The same applies to some types of pesticides. Further environmental and compound specific parameters that influence on biodegradation include biodegrability, bio-availability and concentration of the contaminant, soil temperature, oxygen content, water content and nutrients content. Thus within the context of the Water Framework Directive and ecological status, the uncertainties associated to geochemical environmental characterisation important to potential leaching of contaminant is large and highly pollutant specific. Numerical modelling of organic pollutant leaching to groundwater is only possible if i) a detailed characterisation of the soil hydraulic and geohydrologic conditions are known, i.e. water content profile, water table elevation and hydraulic conductivity; ii) a good estimate of location, quantity and composition of contaminant is available and iii) good estimates of biodegradation rates for each contaminant are availabe. Søvik and Aagaard (2003) found that most geochemical parameters are distributed normally or lognormally. Typical values and parameter bound cannot be provided due to their site-specific nature. More specific parameters that relate to geochemical conditions substantially add to the overall uncertainty. Overall guidelines with respect to uncertainty in contaminant transport are supplied in the GRACOS report (Grathwohl et al., 2003).

The uncertainty associated with the sorption parameter $\mathrm{Kd}$ can be placed into three major categories (Meyer et al., 2004): i) Experimental uncertainty (errors due to measurements), ii) Sorption process chemistry uncertainty (variation in solution chemistry, i.e. complexation, competitive adsorption and alteration of the adsorption-site chemistry; variation in surface adsorption sites, i.e. mineralogy and surface coatings/fracture fillings), and iii) uncertainty resulting from changing the spatial support from laboratory to field. Wauchope et al. (2002) derived information on the uncertainty in sorption in the form of "rules of thumb". The authors considered that i) the batch experiment probably varies from the true average $\mathrm{Kd}$ in the field of the same soil by a factor of two; ii) the variability in $\mathrm{Kd}$ in the field is to be attributed to variation of the organic matter content in the field and of the organic matter itself and typically has a CV of approximately 50\%; (3) a Kd determined for different soils will vary by approximately one order of magnitude; (4) a CV of 30$60 \%$ is common in multi-soil studies and reflects the variability in the sorption capacity of the organic matter and in the measurement of the organic carbon content; and (5) Sorption (Koc) values reported for different studies with multiple soils are expected to vary by an order of magnitude. The application of a similar approach for other key model input parameters would be useful. A number of sensitivity analyses have demonstrated that predictions of pesticide fate models for leaching will mainly be influenced by sorption and degradation parameters (Boesten and van der Linden, 1991; Soutter and Musy, 1998; Dubus et al., 2003) and hydrological parameters (Dubus and Brown, 2002; Wolt et al., 2002).

\section{Spatial- and temporal variability}

Uncertainty in soil physical and geochemical data at the river basin scale will arise from the spatial and temporal variability of environmental variables, from sampling procedures in the field, and from analysis in the laboratory and may also be human induced. Soil variability is the product of soilforming factors operating and interacting over a range of spatial and temporal scales. Heuvelink and Webster (2001) provide a thorough review of spatial and temporal variability and used techniques to analyse them. Soil properties vary in time, but usually so slowly that it can be ignored at time scales common for hydrological studies. Agricultural management practices can significantly affect the structure of the soil and thereby structure dependent soil hydraulic properties such as preferential flow in space and time (e.g. Green et al., 2003). Frost and thaw cycles may also alter soil structure and thereby the soil physical properties (Hinman and Bisal, 1968; Moore, 1981). Recognition of the importance of spatial variability on land-use has led to the study of soil heterogeneity. In agriculture, information about the spatial structure of soil chemical and physical properties is needed to evaluate potential crop yield. In environmental science, knowledge of soil variability is needed for practical applications such as hydrologic modelling work. For example, selection of a suitable remediation method with regard to a contaminated site, as well as its implementation, requires knowledge of the heterogeneity of the properties affecting transport and degradation of pollutants. Previous work on soil heterogeneity related to environmental issues have often focused on the saturated hydraulic conductivity as this property is assumed to be one of the most important transport related properties. (Søvik and Aagaard, 2003). Mulla and McBratney (2000) compiled values for the coefficient of variation for selected soil properties using data from Jury (1986), Jury et al. (1987), Beven et al. (1993) and Wollenhaupt et al. (1997) classified according to typical CV ranges (Wilding, 1985). A summary of their findings is shown in Table 1.

\section{Characterisation of uncertainty in environmental data}

A general framework for assessing and representing uncertainties in environmental data is provided by Brown (2004). 
Table 1. CV and magnitude of variability for selected properties (adapted from Mulla and McBratney, 2000).

\begin{tabular}{lll}
\hline Soil property & CV $(\%)$ & Magnitude of variability \\
\hline pH & $2-15$ & Low \\
Porosity & $7-11$ & Low \\
Bulk density & $3-26$ & Low to moderate \\
\% sand & $3-37$ & Low to moderate \\
0.01 MPa water content & $4-20$ & Low to moderate \\
Pesticide adsorption coeff. & $12-31$ & Moderate \\
Soil Organic Matter (SOM) & $21-41$ & Moderate to high \\
1.5 MPa water content & $14-45$ & Moderate to high \\
$\%$ clay & $16-53$ & Moderate to high \\
Soil Nitrate N & $28-58$ & Moderate to high \\
Soil water infiltration rate & $23-97$ & Moderate to high \\
Soil available potassium (K) & $39-157$ & High \\
Soil available phosphorus (P) & $39-157$ & High \\
Soil electrical conductivity & $91-263$ & High \\
Saturated hydraulic conductivity & $48-352$ & High \\
Solute dispersion coeff. & $79-178$ & High \\
Solute dispersivity & $78-539$ & High \\
\hline
\end{tabular}

In this framework, a coding of attribute uncertainty categories is proposed in which a measurement scale can be:

- continuous numerical, e.g. monthly precipitation data

- discrete numerical, e.g. number of rain gauges in a catchment

- categorical, e.g. soil type

All of these measurement scales may or may not vary in space and/or time.

A distinction is made how uncertainty can be described, i.e. whether this can be done by means of i) probability distributions or upper and lower bound, ii) some qualitative indication of uncertainty, or iii) some indication of how a variable may vary. Further, the "methodological quality" of an uncertain variable can be assessed by expert judgement, e.g. whether or not instruments used are reliable and to what degree, or whether or not experiment for measuring an uncertain variable where properly conducted. Finally, the "longevity" of uncertain information can be evaluated, i.e. to what extend does the information on the uncertainty of a variable change over time.

In the following, selected variables from Table 1 are classified according to their uncertainty category, type of empirical uncertainty, methodological quality and longevity as well as data support, i.e. typical sample size (Table 2). In Table 3 the classification of uncertainty is provided for various derived hydraulic properties as well as the data support. In Tables 2, 3 and 4 the uncertainty category for all variables and parameters except one are judged to be $\mathrm{C} 1$, i.e. continous numerical and varying in space, not in time. The methodological quality for all parameters is classified as "I3", "S3" and "O4" as instruments used are well suited for field experiments, sample design adequate and approved standard in well established discipline. Longevity is judged to be "L2" as the associated uncertainty does not change significantly over time and in principle no updating is required. For example, within the timeframe of the implementation of an operational plan such as the EU Water Framework Directive (approximately 20 years), the uncertainty of a soil physical property classified as L2 is regarded as constant. However, close to the soil surface, properties may change significantly over time due to agricultural practice. This is not accounted for here as properties are considered to be of inherent character. At depths deeper than the A- and perhaps B-horizon geochemical properties are more stable over time.

\section{Spatial support for soil physical properties}

Handling spatial heterogeneity, the existence of preferred time and space scales for soil processes, and approaches to finding linkages between scales of state variables, parameters and conceptualizations have been topics for research for quite a while and a review of recent ideas in this field is well beyond the scope of this paper. Blöschl and Sivapalan (1995) provide a thorough review of scale issues in hydrological modeling and Pachepsky et al. (2003) on scaling methods in soil physics. Modelling of soil processes at the scale of the river basin involves the use of measured soil data at different scales and upscale information to the scale of the applied model. Heuvelink and Pebesma (1999) distinguish between aggregation and disaggregation versus upscaling and downscaling, where the latter is related to modeling. In this context it is convenient to refer to the "support" being defined as the integration volume or aggregation level and often in literature a synonym to "scale". The notion of support is important to characterize and relate different scales in soil physics. Any research of soil physical properties is made with specific support and spatial spacing, the latter being distance between sampling locations. If properties are to be used with different support, e.g. when model inputs require a different support than the support of the observations, scaling becomes necessary (Heuvelink and Pebesma, 1999; Zhu and Mohanty, 2003). Soil samples taken in the field for determination of soil physical properties are typically in the order of magnitude of $100 \mathrm{~cm}^{3}$. For clayey soils larger samples would be more appropriate in order to capture preferential pathways (e.g. Kay and Angers, 2003). Simulation models are support dependent (e.g. Heuvelink and Pebesma, 1999) and field data sampled for model input is often at a support much smaller than the support of interest for model output. Therefore it is needed to aggregate to move from point support to, say, field support. First aggregating point support to field support and then running a hydrological model, or by first running the model using point support data and then aggregating the model results may do this. Usually, the models used are 
Table 2. Classification of uncertainty in texture related properties. For explanation of used codes please refer to the text.

\begin{tabular}{lllllll}
\hline Name & Abbrev. & $\begin{array}{l}\text { Uncertainty } \\
\text { category }\end{array}$ & $\begin{array}{l}\text { Type of em- } \\
\text { pirical uncer- } \\
\text { tainty }\end{array}$ & $\begin{array}{l}\text { Methodological Longevity } \\
\text { quality }\end{array}$ & $\begin{array}{l}\text { Data support } \\
\text { (sample size) }\end{array}$ \\
\hline $\begin{array}{l}\text { Bulk density } \\
\begin{array}{l}\text { Organic matter } \\
\text { content }\end{array}\end{array}$ & RHO & C1 & M1 & I3, S3, O4 & L2 & $100 \mathrm{~cm}^{3}$ \\
Porosity & D1 & M1 & I3, S3, O4 & L2 & $100 \mathrm{~cm}^{3}$ \\
\hline
\end{tabular}

Table 3. Classification of uncertainty in derived hydraulic properties. For explanation of used codes please refer to the text.

\begin{tabular}{lllllll}
\hline Name & Abb. & $\begin{array}{l}\text { Uncertainty } \\
\text { category }\end{array}$ & $\begin{array}{l}\text { Type of em- } \\
\text { pirical uncer- } \\
\text { tainty }\end{array}$ & $\begin{array}{l}\text { Methodological Longevity } \\
\text { quality }\end{array}$ & $\begin{array}{l}\text { Data support } \\
\text { (sample size) }\end{array}$ \\
\hline Saturated water content & $\theta_{s}$ & $\mathrm{C} 1$ & $\mathrm{M} 1$ & $\mathrm{I} 3, \mathrm{~S} 3, \mathrm{O} 4$ & $\mathrm{~L} 2$ & $100 \mathrm{~cm}^{3}$ \\
Residual water content & $\theta_{r}$ & $\mathrm{C} 1$ & $\mathrm{M} 1$ & $\mathrm{I}, \mathrm{S} 3, \mathrm{O} 4$ & $\mathrm{~L} 2$ & $100 \mathrm{~cm}^{3}$ \\
vG fitting parameter & $\alpha$ & $\mathrm{C} 1$ & $\mathrm{M} 1$ & $\mathrm{I} 3, \mathrm{~S} 3, \mathrm{O} 4$ & $\mathrm{~L} 2$ & $100 \mathrm{~cm}^{3}$ \\
vG fitting parameter & $\mathrm{n}$ & $\mathrm{C} 1$ & $\mathrm{M} 1$ & $\mathrm{I} 3, \mathrm{~S} 3, \mathrm{O} 4$ & $\mathrm{~L} 2$ & $100 \mathrm{~cm}^{3}$ \\
B\&C air entry pressure & $\psi_{c}$ & $\mathrm{C} 1$ & $\mathrm{M} 1$ & $\mathrm{I}, \mathrm{S} 3, \mathrm{O} 4$ & $\mathrm{~L} 2$ & $100 \mathrm{~cm}^{3}$ \\
B\&C pore size distr.index & $\lambda$ & $\mathrm{C} 1$ & $\mathrm{M} 1$ & $\mathrm{I} 3, \mathrm{~S} 3, \mathrm{O} 4$ & $\mathrm{~L} 2$ & $100 \mathrm{~cm}^{3}$ \\
Campb. fitting parameter & $\mathrm{b}$ & $\mathrm{C} 1$ & $\mathrm{M} 1$ & $\mathrm{I}, \mathrm{S} 3, \mathrm{O} 4$ & $\mathrm{~L} 2$ & $100 \mathrm{~cm}^{3}$ \\
Saturated conductivity & $\mathrm{K}_{\text {sat }}$ & $\mathrm{C} 1$ & $\mathrm{M} 1$ & $\mathrm{I} 3, \mathrm{~S} 3, \mathrm{O} 4$ & $\mathrm{~L} 2$ & $100-10000 \mathrm{~cm}^{3}$ \\
\hline
\end{tabular}

non-linear and the two alternatives for aggregation will not yield the same result (e.g. Addiscot, 1993; Heuvelink, 1998). It is important to note that coarse-scale (river basin scale) models often use parameters that do not have analogues at finer scales in which case upscaling is not relevant. Therefore, it is needed to adapt and recalibrate the original model because functional relationships are typically non-linear and process controls usually change with scale (Addiscott and Tuck, 2001; Brown and Heuvelink, 2005). Deriving parameters for closed-form soil water retention expressions like the Gardner-Russo (Gardner, 1958; Russo, 1988), the Brooks and Corey (Brooks and Corey, 1964), Campbell (Campell, 1974) or van Genuchten model (van Genuchten, 1980) may be done by means of PTFs based on i) a spatial classification of soil texture by general purpose soil maps or by ii) spatial interpolation of soil data. Advantages and disadvantages of both methods are discussed in Heuvelink and Webster (2001). Variability within soil mapping units is also described in Mulla and McBratney (2000) where they identify two types of variation of soil physical properties: i) soil variability within soil mapping units, and ii) variability caused by mapping and classification error. For most of the soil mapping in the U.S. the scale allows up to $40 \%$ of the region within a soil mapping unit to consist of dissimilar inclusions.

A large number of articles have reported on the spatial variability of pesticide residues or leaching in the field as mentioned in the review paper by Dubus et al. (2003). Also a number of leaching-risk studies have attempted to account for soil variability within map units to predict leaching of nitrate (Gorres and Gold, 1996; Richter et al., 1998; Webb and Lilburne, 2005). The above-mentioned works have been attributed to some extent to the variability in space of soil physical and geochemical properties, which in turn influence predictions of both nitrate and pesticide leaching models. Causes of spatial variability are traditionally classified into intrinsic or extrinsic factors. Taking the agricultural soil system as an example, intrinsic variability is the variability caused by natural conditions in soil whereas extrinsic variability is that imposed on a field as part of land management practices. Examples of soil characteristics that exhibit intrinsic variations are texture and mineralogy while tillage, fertilizer and pesticide applications, harvesting and removal of crop residues all contribute to the development of an extrinsic variability.

\section{Geostatistics for representing spatial variation}

Often, soil properties do not occur across the landscape in a random fashion. Soil physical properties taken at close spacings will be similar or spatially correlated whereas samples from distant samples may be dissimilar and spatially 
Table 4. Classification of uncertainty in geochemical properties. For explanation of used codes please refer to the text.

\begin{tabular}{|c|c|c|c|c|c|c|}
\hline Name & Abbrev. & $\begin{array}{l}\text { Uncertainty } \\
\text { category }\end{array}$ & $\begin{array}{l}\text { Type of em- } \\
\text { pirical uncer- } \\
\text { tainty }\end{array}$ & $\begin{array}{l}\text { Methodological } \\
\text { quality }\end{array}$ & Longevity & $\begin{array}{l}\text { Data support } \\
\text { (sample size) }\end{array}$ \\
\hline Total phosphorus & ТОTP & $\mathrm{C} 1$ & M1 & $\mathrm{I} 3, \mathrm{~S} 3, \mathrm{O} 4$ & L2 & $100 \mathrm{~cm}^{3}$ \\
\hline Ferro oxides & FE-O & $\mathrm{C} 1$ & M1 & $\mathrm{I} 3, \mathrm{~S} 3, \mathrm{O} 4$ & L2 & $100 \mathrm{~cm}^{3}$ \\
\hline Aluminium oxides & AL-O & $\mathrm{C} 1$ & M1 & $\mathrm{I} 3, \mathrm{~S} 3, \mathrm{O} 4$ & L2 & $100 \mathrm{~cm}^{3}$ \\
\hline Phosphorus ferro oxides & FE-P & $\mathrm{C} 1$ & M1 & $\mathrm{I} 3, \mathrm{~S} 3, \mathrm{O} 4$ & L2 & $100 \mathrm{~cm}^{3}$ \\
\hline Phosphorus alu oxides & AL-P & $\mathrm{C} 1$ & M1 & $\mathrm{I} 3, \mathrm{~S} 3, \mathrm{O} 4$ & L2 & $100 \mathrm{~cm}^{3}$ \\
\hline $\mathrm{CEC}$ & CEC & $\mathrm{C} 1$ & M1 & $\mathrm{I} 3, \mathrm{~S} 3, \mathrm{O} 4$ & L2 & $100 \mathrm{~cm}^{3}$ \\
\hline $\mathrm{CaCO}_{3}$ & $\mathrm{CaCO}_{3}$ & $\mathrm{C} 1$ & M1 & $\mathrm{I} 3, \mathrm{~S} 3, \mathrm{O} 4$ & L2 & $100 \mathrm{~cm}^{3}$ \\
\hline $\mathrm{PH}$ & $\mathrm{pH}$ & $\mathrm{C} 1$ & M1 & $\mathrm{I} 3, \mathrm{~S} 3, \mathrm{O} 4$ & L2 & $100 \mathrm{~cm}^{3}$ \\
\hline
\end{tabular}

uncorrelated. The spatial correlation structure of soil physical- and chemical properties can be used to estimate properties at unsampled locations by means of geostatistics (Journel and Huijbregts, 1978; Hamlett et al., 1986; Isaaks and Srivastava, 1989; Cressie, 1991). An introduction to geostatistics applied to soil science is provided by e.g. Heuvelink and Webster (2001) and a textbook by Nielsen and Wendroth (2003). Only the very essential theory needed for understanding the principle of autocorrelation is repeated below. Input for distributed hydrological modeling at the river basin scale typically requires that available sampled data at point support is aggregated to block support data that is compatible with the model grid scale. For soil physical properties this usually involves modeling the spatial correlation structure using the semi-variogram $\gamma(\mathrm{h})$ (Burgess and Webster, 1980) followed by spatial interpolation (kriging).

$\gamma(h)=\frac{1}{2 n(h)} \sum_{i=1}^{n(h)}\left[z_{i}-z_{i}+h\right]^{2}$

Where $h$ is the separation distance between the measured soil properties $z_{i}$ and $z_{i+h}$ at locations $x_{i}$ and $x_{i+h}$. The number of pairs separated at distance $h$ is denoted $n(h)$. In Eq. (1) it is implicitly assumed that $\gamma(\mathrm{h})$ is only dependent on $h$ and not on the positions $x_{i}$ and $x_{i+h}$. At very small separation distances, observations should become very similar and the semivariogram, i.e. the variance of $\left(z_{i}, z_{i}+h\right)$ theoretically approaches zero. In practice there will often be an intercept (the nugget) that accounts for the uncorrelated component of the variance as well as random measurement errors. At larger distances $h$, the semivariance typically flattens out and becomes constant, i.e. observations become uncorrelated. The distance $h$ where this occurs is called the range. The semivariogram can also be expressed by the autocorrelation function, which is related to the semivariogram by:

$\gamma(h)=s^{2}[1-\rho(h)]$

Where $s^{2}$ is the process variance and $\rho(h)$ is the autocorrelation function. The semivariogram can be modelled by fitting experimental sampling data to a model. The most common models in this respect are the linear, spherical and exponential. If experimental data is not available then one must rely on values for typical autocorrelation lengths from the literature in order to do spatial interpolation (kriging). Describing uncertainty using geostatistics is not an activity exempt from uncertainty itself as variogram uncertainty may be large (Jansen, 1998) and spatial interpolation may be undertaken using different techniques.

\section{Experimental autocorrelation length scales for soil physical properties}

In this section an overview of experimentally determined autocorrelation length scales is provided and summarized in Tables 5, 6 and 7. Russo and Bresler (1981) reported length scales for several hydraulic properties: $21 \mathrm{~m}$ for saturated hydraulic conductivity $\left(K_{\text {sat }}\right), 55 \mathrm{~m}$ for saturated water content, $25 \mathrm{~m}$ for residual water content and $35 \mathrm{~m}$ for sorptivity. Later Vauclin et al. (1983) found correlation length values around $25 \mathrm{~m}$ for water content at $\mathrm{pF} 2.5$. Cook et al. (1989) found a range of $120 \mathrm{~m}$ for the recharge rate of groundwater in Australia as related to saturated conductivity. A joint research project in Denmark (Jensen and Refsgaard, 1991a, b) investigated and described the nature of the spatial variability of some soil physical properties on the basis of detailed experimental studies on two different localities, a clayey and sandy site, and at different depths by means of geostatistical methods. They found no textural spatial dependence for the clayey site nor for porosity, dry bulk density and $K_{\text {sat }}$, whereas the available water content showed spatial dependence for all depths. At the sandy site, no spatial depence was found for silt, humus, dry bulk density, porosity and soil water characteristics at $10 \mathrm{kPa}$. For clay, correlation lengths of $20 \mathrm{~m}$ have been reported and for fine sand and coarse sand approximately $45 \mathrm{~m}$. Mohanty et al. (1994) conducted a spatial analysis of measured hydraulic 
Table 5. Autocorrelation length scales (ranges) for soil physical properties.

\begin{tabular}{|c|c|c|c|c|}
\hline Name & Symbol & $\gamma(\mathrm{h})$ model & range $(\mathrm{m})^{*}$ & reference \\
\hline Clay content & $\%$ Clay & $\begin{array}{l}\text { Stepwise } \text { linear }^{1} \text {, } \\
\text { spherical }^{2} \\
\text { Exp. }^{3}\end{array}$ & $\begin{array}{l}15-40^{1}, 20-33^{2} \\
69^{3}\end{array}$ & $\begin{array}{l}{ }^{1} \text { Jensen and Refsgaard } \\
(1991 \mathrm{a}, \quad \mathrm{b}),{ }^{2} \text { Neuman and } \\
\text { Wierenga (2003), }{ }^{3} \mathrm{McBratney} \\
\text { and Pringle (1999) }\end{array}$ \\
\hline Silt content & $\%$ Silt & Spherical $^{2}$ & N/A ${ }^{1}, 20-26^{2}$ & $\begin{array}{l}{ }^{1} \text { Jensen and Refsgaard } \\
(1991 \mathrm{a}, \mathrm{b}),{ }^{2} \text { Neuman and } \\
\text { Wierenga (2003) }\end{array}$ \\
\hline Sand content & $\%$ Sand & $\begin{array}{l}\text { Stepwise } \text { linear }^{2} \text {, } \\
\text { spherical }^{3} \\
\text { Exp. }^{4}\end{array}$ & $\begin{array}{l}1-34^{1}, 15-40^{2}, 20-35^{3} \\
75^{4}\end{array}$ & $\begin{array}{l}{ }^{1} \text { Mulla and McBratney } \\
(2000),{ }^{2} \text { Jensen and Refsgaard } \\
(1991 \mathrm{a}, \quad b),{ }^{3} \text { Neuman and } \\
\text { Wierenga (2003), }{ }^{4} \text { McBratney } \\
\text { and Pringle (1999) }\end{array}$ \\
\hline Bulk density & $\mathrm{RHO}, \rho$ & none ${ }^{1}, \exp ^{2}$ & N/A ${ }^{1}, 37-39^{2}$ & $\begin{array}{l}{ }^{1} \text { Jensen and Refsgaard } \\
(1991 \mathrm{a}, \quad \mathrm{b}),{ }^{2} \text { Kristensen et } \\
\text { al. (1995) }\end{array}$ \\
\hline $\begin{array}{l}\text { Organic matter } \\
\text { content }\end{array}$ & SOM & exp. $^{2}$, sperical $^{9}$ & $34-45^{2}, 112-250^{9}$ & $\begin{array}{l}{ }^{2} \text { Kristensen et al. (1995), } \\
{ }^{9} \text { Mulla and McBratney (2000) }\end{array}$ \\
\hline Porosity & POR & none $^{1}$, spherical $^{4}$ & N/A ${ }^{1}, 55^{3 \mathrm{a}}, 14-76^{9 \mathrm{a}}$ & $\begin{array}{l}{ }^{1} \text { Jensen and }{ }^{2} \text { Refsgaard } \\
\left(1991 \mathrm{a}, \quad \text { b), }{ }^{3} \text { Russo and }\right. \\
\text { Bresler (1981), }{ }^{9} \text { Mulla and } \\
\text { McBratney (2000) }\end{array}$ \\
\hline $\begin{array}{l}\text { Soil water } \\
\text { characteristics } 1 \mathrm{~b}, 2 \mathrm{c}\end{array}$ & SWC & $\begin{array}{l}\text { Stepwise } \\
\text { spherical }^{2}\end{array}$ linear ${ }^{1}$, & $25-40^{1}, 375-1285^{2}$ & $\begin{array}{l}{ }^{1} \text { Jensen and Refsgaard } \\
\left(1991 \mathrm{a}, \text { b), }{ }^{2} \text { Romano and }\right. \\
\text { Santini (1997) }\end{array}$ \\
\hline
\end{tabular}

a: for saturated water content

b: water content $(\mathrm{WC})$ at $-10,-32,-100,-316,-1000$ and $-15850 \mathrm{kPa}$; AWC (WC_100 kPa - WC_ $15850 \mathrm{kPa})$; $\ln (\mathrm{Ksat})$

c: WC at $-1,-10$ and $-100 \mathrm{kPa}$

conductivity using disc infiltrometers and found no spatial dependence for $K_{\text {sat }}$ and the van Genuchten retention parameter. Kristensen et al. (1995) studied two fields in Denmark representing sandy loam and a sandy clay loam within the context of site specific farming. They derived correlation lengths for a number of soil physical and chemical parameters. Romano and Santini (1997) analysed within the Basilicata area in Southern Italy semivariogram models for curve fitted (RETC; van Genuchten et al., 1991) and estimated retention characteristics using a PTF approach (Gupta and Larson, 1979; Rawls et al., 1982; Rawls and Brakensiek, 1989; Vereecken et al., 1989). They arrived at spherical semi-variogram models and ranges between 800 and $1300 \mathrm{~m}$ for both fitted and PTF estimated water retention data. Neuman and Wierenga (2003) used omnidirectional sample variograms and fitted spherical models for percent sand, silt and clay at depths $0-30 \mathrm{~cm}$. Similar variograms for underlying $30-180 \mathrm{~cm}$ can be found in Wang (2002). Some appeared to fit a linear or Gaussian model, but most fitted spherical models with ranges of $20-25 \mathrm{~m}$. They also conducted a variogram analysis of the hydraulic parameters $K_{\text {sat }}$ and saturated water content $\left(\theta_{s}\right)$ obtained by neural network software package ROSETTA (Schaap et al., 2001). Most of them fit- ted spherical models with ranges between 20 and $36 \mathrm{~m}$. Recently Sobieraj et al. (2004) studied scale dependency in spatial patterns of saturated conductivity in a tropical rainforest catena and a list of previous studies on the spatial structure of $K_{\text {sat }}$ and correlation lengths varying from 1-25 m. Leij et al. (2004) found that topographic attributes can be used to improve the prediction of soil hydraulic properties using PTFs and neural network techniques. Within the context of spatial structure of soil physical structure and agriculture Delcourt et al. (1996) studied the spatial structure of soil nutrients from two fields in the main agricultural area in Belgium and reported geostatistical parameters for some topsoil nutrients. Later McBratney and Pringle (1999) conducted a literature review on variograms for soil- and soil chemical properties for use in precision agriculture. In their study they presented an overview of variograms for $\mathrm{pH}$, clay- and sand content, carbon-, $\mathrm{NO}_{3}-\mathrm{N}$-, phosphorus- and potassium content in the soil. Mulla and McBratney (2003) compiled various sources of experimental work on semivariogram models for several measured soil and agronomic properties from Jury (1986), Warrick et al. (1986), Wollenhaupt et al. (1997) and McBratney and Pringle (1997). These results and others are summarized in Tables 5-7. Geostatistical analyses have also been 
Table 6. Autocorrelation length scales (ranges) for derived soil hydraulic properties.

\begin{tabular}{|c|c|c|c|c|}
\hline Name & Symbol & $\gamma(\mathrm{h})$ model & range $(\mathrm{m})^{*}$ & reference \\
\hline Saturated water content & $\theta_{s}$ & Spherical ${ }^{1,4}$ & $\begin{array}{l}800-900^{1 \mathrm{a}}, 55^{2 \mathrm{~b}}, 14- \\
76^{3}, 20-36^{4}\end{array}$ & $\begin{array}{l}{ }^{1} \text { Romano and Santini (1997), } \\
{ }^{2} \text { Russo and Bresler (1981), }{ }^{3} \text { Mulla } \\
\text { and McBratney (2000), }{ }^{4} \text { Neuman } \\
\text { and Wierenga (2003) }\end{array}$ \\
\hline Residual water content & $\theta_{r}$ & Spherical $^{1 \mathrm{c}}$ & $25^{1 \mathrm{c}, 2}, 10-50^{3 \mathrm{~d}}$ & $\begin{array}{l}{ }^{1} \text { Vauclin et al. (1983), }{ }^{2} \text { Russo and } \\
\text { Bresler (1981), }{ }^{3} \text { Jensen and Refs- } \\
\text { gaard (1989) }\end{array}$ \\
\hline vG fitting parameter & $\alpha$ & $\mathrm{N} / \mathrm{A}^{1}$, spherical $^{2 \mathrm{c}}$ & $\mathrm{N} / \mathrm{A}^{1}, 25^{2 \mathrm{c}}$ & $\begin{array}{l}{ }^{1} \text { Mohanty et al. (1994), }{ }^{2} \text { Vauclin et } \\
\text { al. (1983) }\end{array}$ \\
\hline vG fitting parameter & $\mathrm{n}$ & Spherical $^{1 \mathrm{c}}$ & $25^{1 \mathrm{c}}$ & ${ }^{1}$ Vauclin et al. (1983) \\
\hline $\mathrm{B} \& \mathrm{C}$ air entry pressure & $\psi_{\mathrm{c}}$ & spherical ${ }^{1 \mathrm{c}}$ & $25^{1 \mathrm{c}}$ & ${ }^{1}$ Vauclin et al. (1983) \\
\hline $\mathrm{B} \& \mathrm{C}$ pore size distr.index & $\lambda$ & $\mathrm{N} / \mathrm{A}^{1 \mathrm{e}}$, spherical $^{2 \mathrm{c}}$ & $\mathrm{N} / \mathrm{A}^{1 \mathrm{e}}, 25^{2 \mathrm{c}}$ & $\begin{array}{l}{ }^{1} \text { Mohanty et al. (1994), }{ }^{2} \text { Vauclin et } \\
\text { al. (1983) }\end{array}$ \\
\hline Campb. fitting parameter & $\mathrm{b}$ & Spherical $^{1 \mathrm{c}, 2 \mathrm{f}}$ & $25^{1 \mathrm{c}}$ & $\begin{array}{l}{ }^{1} \text { Vauclin et al. (1983), }{ }^{2} \text { Meyer et } \\
\text { al. (1997) }\end{array}$ \\
\hline Saturated conductivity & $\mathrm{K}_{\text {Sat }}$ & Spherical $^{1 \mathrm{~g}}$ & $\begin{array}{l}21^{2,3}, 120^{1 \mathrm{~g}}, \mathrm{~N} / \mathrm{A}^{4} \\
25-40^{5}, 1-34^{6}, 20- \\
36^{7}, 1-25^{8}\end{array}$ & $\begin{array}{l}{ }^{1} \text { Cook et al. (1989), }{ }^{2} \text { Russo } \\
\text { and Bresler (1981), }{ }^{3} \text { Vauclin et } \\
\text { al. (1983), }{ }^{4} \text { Mohanty et al. (1994), } \\
{ }^{5} \text { Jensen and Refsgaard (1989), } \\
{ }^{6} \text { Mulla and McBratney (2000), } \\
{ }^{7} \text { Neuman and Wierenga (2003), } \\
{ }^{8} \text { Sobieraj et al. (2004) }\end{array}$ \\
\hline
\end{tabular}

a: water content at $-1 \mathrm{kPa}$

b: for saturated water content

c: water content at $\mathrm{pF} 2.5$

$\mathrm{d}$ : in general for retention parameters

e: through $n=\lambda+1$

f: relation between $\mathrm{b}$ and $\psi_{c}$ and $\lambda$

g: groundwater recharge rate

: in horizontal direction

performed to study the spatial variability of pesticide sorption (e.g. Jacques et al., 1999) and degradation (e.g. Walker et al., 2001) in the field. Also soil nitrate has been geostatistical analysed with respect to the content in the topsoil (e.g. Huang et al., 2004), in the soil profile (e.g. Shahandeh et al., 2004), or in the whole vadose zone (e.g. Onsoy et al., 2004).

\section{Uncertainty related to derivation of soil hydraulic properties for hydrological model input}

Water retention and hydraulic conductivity are crucial input parameters in any modelling study on water flow and solute transport in soils. Uncertainty involved in deriving soil hydraulic properties from pedotransfer techniques is discussed in this section. In Table 6 examples of parameters are listed which are of large importance for hydrologic studies with focus on parameterization of modelling tools for describing water- and contaminant flow through the unsaturated zone towards the groundwater zone. All hy- draulic properties and thus derived model parameters relate to soil composition and are highly uncertain at the river basin scale as soil texture data is usually extracted from regional databases and is based on measurements from soil profiles that may be located a quite long apart. Derivation of soil hydraulic properties for input to modelling tools either by i) soil class PTFs, e.g. Carsel and Parrish (1988) and Wösten et al. (1995), ii) linear/non-linear regression equations (regression PTFs), e.g. Rawls and Brakensiek (1985) or Minasny et al. (1999) iii) curve fitting, e.g. RETC (van Genuchten et al., 1991) or finally iv) through the neural network approach, e.g. ROSETTA (Schaap et al., 2001) are all associated with substantial uncertainty. PTFs transfer experimentally collected data, usually texture properties (but also variables like organic matter or $\mathrm{pH}$ ), to parameters required by numerical models. In most cases such parameters are related to hydraulic properties, but PTF may also predict soil chemical characteristics, e.g. CEC, soil phosphorus and adsorptiondesorption parameters (Wösten et al., 2001) as well as mechanical and biological properties (McBratney et al., 2002). 
Table 7. Autocorrelation length scales (ranges) for geochemical properties.

\begin{tabular}{|c|c|c|c|c|}
\hline Name & Abbrev. & $\gamma(\mathrm{h})$ model & range $(\mathrm{m})^{*}$ & reference \\
\hline Soil Nitrate-N & $\mathrm{NO}_{3}-\mathrm{N}$ & spherical/exp ${ }^{2,3}$ & $\begin{array}{l}40-275^{1} \\
31-120^{2} \\
52^{3}\end{array}$ & $\begin{array}{l}{ }^{1} \text { Mulla and McBratney (2000) } \\
{ }^{2} \text { Shahandeh et al. (2005) } \\
{ }^{3} \text { McBratney and Pringle (1999) }\end{array}$ \\
\hline Carbon & $\mathrm{C}$ & Spherical $^{1}$ & $50^{1}$ & ${ }^{1}$ McBratney and Pringle (1999) \\
\hline $\begin{array}{l}\text { Soil available potas- } \\
\text { sium }\end{array}$ & $\mathrm{K}$ & Spherical $^{2}$ & $\begin{array}{l}75-428^{1} \\
11.4^{2}\end{array}$ & $\begin{array}{l}{ }^{1} \text { Mulla and McBratney (2000) } \\
{ }^{2} \text { McBratney and Pringle (1999) }\end{array}$ \\
\hline Total phosphorus & TOTP & $\begin{array}{l}\text { linear/exp. } \\
\text { gaussian }^{1,2} \\
\text { spherical }^{5}\end{array}$ & $\begin{array}{l}63^{1}, \quad 150-500^{2}, \\
55^{3}, 68-260^{9} \\
19.3^{5}\end{array}$ & $\begin{array}{l}{ }^{1} \text { Delcourt et al. }(1996),{ }^{2} \text { Kristensen et } \\
\text { al. (1995), }{ }^{3} \text { Klironomos et al. (1999), }{ }^{4} \text { Mulla } \\
\text { and McBratney (2000) } \\
{ }^{5} \text { McBratney and Pringle (1999) }\end{array}$ \\
\hline Ferro oxides & FE-O & $\operatorname{Exp}^{1}$ & 1.7 & ${ }^{1}$ Søvik and Aagaard (2003) \\
\hline Aluminium oxides & AL-O & $\operatorname{Exp}^{1}$ & $0.48^{1}$ & ${ }^{1}$ Søvik and Aagaard (2003) \\
\hline $\begin{array}{l}\text { Phosphorus ferro ox- } \\
\text { ides }\end{array}$ & FE-P & N/A ${ }^{1}$ & $\mathrm{~N} / \mathrm{A}^{1}$ & ${ }^{1}$ Søvik and Aagaard (2003) \\
\hline Phosphorus alu oxides & AL-P & $\mathrm{N} / \mathrm{A}^{1}$ & $\mathrm{~N} / \mathrm{A}^{1}$ & ${ }^{1}$ Søvik and Aagaard (2003) \\
\hline $\mathrm{CEC}$ & CEC & $\operatorname{Exp}^{1}$ & $7.5^{1}$ & ${ }^{1}$ Barbizzi et al. (2004) \\
\hline Soil pH & $\mathrm{pH}$ & $\operatorname{Exp}^{2}$ & $\begin{array}{l}20-260^{1} \\
62^{2}\end{array}$ & $\begin{array}{l}{ }^{1} \text { Mulla and McBratney (2000) } \\
{ }^{2} \text { McBratney and Pringle (1999) }\end{array}$ \\
\hline $\mathrm{CaCO}_{3}$ & $\mathrm{CaCO}_{3}$ & linear/exp ${ }^{1}$ & $30^{1}$ & ${ }^{1}$ Kristensen et al. (1995) \\
\hline
\end{tabular}

*: in horizontal direction

As opposed to the categorical (USDA soil classes) soil physical parameter estimation, PTFs usually are continous functions for providing such estimates. Wösten et al. (2001) reviews PTFs based on the European HYPRES (Wösten et al., 1999) and the international UNSODA (Leij et al., 1996; Nemes et al., 2001) databases. PTFs may require a fixed dataset, e.g. textural properties or be hierarchical depending on the available data input (Schaap et al., 1998, 2001). McBratney et al. (2002) developed a decision support system in which PTFs are automatically selected to ensure a minimum variance and return soil physical and chemical properties with their uncertainties based on the information provided. They also provide a comprehensive review of PTFs and related uncertainty. This uncertainty can be due to the uncertainty of the PTF model itself and to uncertainty in the input data. The uncertainty associated with the model can be calculated from the non-parametric bootstrap method (Efron and Tibshirani, 1993). The uncertainty of the input data can be computed using Monte Carlo simulation. This is done by sampling repeatedly from the assumed distribution of the input data and evaluation of the output of the PTF model. Vereecken et al. (1992) performed a functional evaluation of PTFs by examining the uncertainty in PTF model structure related to moisture supply capacity (MSC) and downward flux (DF) below the rootzone using a hydrological model and the Monte Carlo technique. They found that an improved estimate of the hydraulic properties, obtained by calibrating the PTFs using more detailed textural information did not reduce the uncertainty in output MSC and DF from the hy- drological model. It was concluded that more than $90 \%$ of the uncertainty was attributed to uncertainty in the PTF itself overwhelming the uncertainty caused by variability in soil texture. Finke et al. (1996) concluded from a study in the Netherlands that uncertainty in PTFs required adequately capturing the spatial variability of basic soil properties as well as spatial variability of water table depths if leaching of chemicals is studied. Wösten et al. (2001) evaluated accuracy and reliability of PTFs in general and discussed statistical techniques in this respect. Typical examples for PTF accuracy (RMSE) for water retention data were also presented. RMSE of volumetric water content at pressure heads of $-33 \mathrm{kPa}$ and $-1500 \mathrm{kPa}$ ranged for each of those tensions from 0.02 (Pachepsky et al., 1996) to $0.11 \mathrm{~m}^{3} \mathrm{~m}^{-3}$ (Schaap et al., 1998). Wösten et al. (2001) concluded that in general PTFs can be considered to be sufficient accurate and reliable and may be appropiate for many applications on regional and national scale. If PTFs are trained/calibrated adequately, the uncertainty in the model is usually smaller than the uncertainty in the inputs. One may use Latin Hypercube Sampling to sample the multivariate joint distribution of the prediction. This is achieved by sampling repeatedly from the assumed probability distribution of the input variables and evaluating the result of the PTF for each sample. The distribution of the results, along with the mean, standard deviation and other statistical measures can then be estimated. Christiaens et al. (2001) and McBratney et al. (2002) compared uncertainty related to different methods to determine soil hydraulic properties including PTF estimations through USDA soil texture 
classes, continuous PTFs and neural networks in combination with bootstrapping. Moreover, they analysed how this uncertainty is propagated in the distributed hydrological MIKE SHE model using a Latin Hypercube approach. Uncertainties of soil physical parameters in the range from 3 to $700 \%$ were found, $K_{\text {sat }}$ and $\theta_{r}$ being the most uncertain. Neural networks performed best in terms of the total error. Schaap and Leij (1998) presented a neural network analysis for hierarchial prediction of soil hydraulic properties. They used 12 neural network models for prediction of soil water retention properties and $K_{\text {sat }}$ and demonstrated that neural network models compared favourably to regression models when tested against independent data. The hierarchical approach has the practical advantage that they permit high flexibility with respect to data input. Uncertainty in predicted soil hydraulic properties can be assessed by combining the neural network approach with the bootstrap method and is incorporated in the ROSETTA software (Schaap et al., 2001). Carsel and Parrish (1988) presented joint probability distributions for the parameters of the van Genuchten (1980) water retention and unsaturated hydraulic conductivity models (Mualem, 1976). These parameters are: saturated volumetric water content, residual volumetric water content, $K_{\text {sat }}$, van Genuchten model parameters $\alpha$ and $n$. Carsel and Parrish (1988) based their analysis on data from soil samples collected by the Natural Resources Conservation Service representing soils from 42 states in USA. Soil measurements used were bulk density, percent sand $(0.05-2 \mathrm{~mm})$, and percent clay $(<0.002 \mathrm{~mm})$. Bulk density was used to infer saturated water content while percent sand and clay, along with saturated water content, were used with the regressions of Rawls and Brakensiek (1985) to estimate the remaining parameters. Carsel and Parrish's soil database included 15737 samples from twelve USDA soil textural classifications. Meyer et al. (1997) resampled the distributions and derived closedform distributions of the soil hydraulic parameters that can be used to represent parameter uncertainty when the information about a soil is limited to its textural class (Meyer et al., 1997). Meyer et al. (2004) listed derived dry bulk density, compiled by Meyer and Gee (1999) from the U.S. Natural Resources Conservation Service Soil Database (NRCSSC) divided according to the USDA soil textural class. For each textural class, the Kolmogorov-Smirnov D-statistic was calculated using hypothetical normal and lognormal distributions. It appeared that a normal distribution fitted the bulk density data best for all textural classes and is therefore recommended. As described previously, for each of the NRCSSC database soil classes, the statistics for the parameters $\theta_{s}, \theta_{r}, \alpha, n$, and $K_{\text {sat }}$ are computed using a multiple regression equation (Carsel and Parrish, 1988). The Brooks and Corey parameters $\psi_{c}$ and $\lambda$ as well as the Campbell $b$ parameter are derived from the first mentioned. Thus for each soil class, the probability density function, the mean, standard deviation (std), lower limit (1l) and upper limit (ul) is provided. Meyer et al. (1997) induced correlations between parameters by applying the correlations between $\theta_{s}, \theta_{r}, \alpha, n$, and $K_{\text {sat }}$ given in Carsel and Parrish (1988). The rank correlation method of Iman and Conover (1982) as employed in the Latin Hypercube sampling code of Iman and Shortencarier (1984) is used. These tables originally presented in Meyer et al. (1997) are well suited for use in generation of Monte Carlo datasets where information on the probability density function as well as mean and variance are required.

\section{Summary and conclusions}

For hydrological modelling studies at the river basin scale there is a clear need to identify, classify, and quantify uncertainties associated to soil physical and soil chemical data in order to guide decision makers in assessing simulations of measures and their implications for policy making. So far very little guidance has been provided on how to cope with uncertainty in data for input to simulation models and uncertainty in the models themselves. The present paper provides guidance by classifying uncertainty in soil physical properties following the scheme proposed by Brown (2004) which groupes uncertainty according to category, type, methodological quality and longevity. Furthermore, spatial support aspects have been reviewed and discussed and autocorrelation length scales for a broad range of soil physical- and geochemical properies are provided as well as suggestions for variogram models required for geostatistical analyses. The scope of this paper is restricted to uncertainty in field data, more specifically soil physical data. A quantification of data uncertainty for soil physical data is of crucial importance for the assessment of the reliability of simulated solute transport through the unsaturated zone to vulnerable groundwater ressources at multiple scales. Environmental studies for hydrologic modelling are typically at the river basin scale and therefore there is a need to know how to handle change of support for data collected at one (usually at a far lesser) scale and the relevant river basin scale. In general for modelling studies, non-linear soil water models can only be used at the support for which they were developed. Estimating soil properties at unsampled points by means of geostatistical techniques require reliable information on the spatial structure of soil data, often expressed by the semi-variogram function. In this paper this information is assessed by reviewing current developments in the field of soil physical data uncertainty and adopting a classification system. Then spatial variability and structure is inspected by reviewing experimental work on determining spatial length scales for soil physical (and soil chemical) data. Quantified length scales enable change of support, e.g. by geostatistically transforming point support data to larger scales relevant for hydrologic modelling studies, i.e. the river basin scale. Finally, the derivation of hydraulic parameters from soil physical data by means of PTFs is considered and uncertainties in this process reviewed. 
It can be concluded that considering uncertainty in soil physical data in environmental hydrologic studies at the river basin scale is not as yet widely practised. Decision-makers who use the results of hydrologic modelling studies to assess the effects of various measures need guidance from modellers on how uncertainty affects hydrologic simulations and what the implications are for policymaking. Through a review process on uncertainty of soil physical properties and by providing information on their spatial structure within an adopted classification system, the present paper provides guidance and support for the assesment of uncertainty towards practitioners within hydrological modelling.

Acknowledgements. This paper builds on results obtained from the EU-FP5 project Harmonised techniques and representative river basin data for assessment and use of uncertainty information in integrated water management (HarmoniRiB) under contract EVK-CT-2002-00109.

Edited by: E. van Loon

\section{References}

Addiscott, T. M. and Tuck, G.: Non-linearity and error in modelling soil processes, European Journal of Soil Science, 52, 129-138, 2001.

Addiscott, T. M.: Simulation modelling and soil behaviour, Geoderma, 60, 15-40, 1993.

Barbizzi, S., de Zorgi, P., Belli, M., Pati, A., Sansone, U., Stellato, L., Barbina, M., Deluisa, A., Menegon, S., and Coletti, V.: Characterisation of a reference site for quantifying uncertainties related to soil mapping, Environ. Pollut., 127 131-135, 2004.

Beulke, S., Dubus, I. G., Brown, C. D., and Gottesbüren, B.: Simulation of pesticide persistence in the field on the basis of laboratory data - a review, J. Environ. Qual., 29, 1371-1379, 2000.

Beven, K. J., Henderson, D. E., and Reeves, A. D.: Dispersion parameters for undisturbed partially saturated soil, J. Hydrol., 143, 19-43, 1993.

Blöschl, G. and Sivapalan, M.: Scale issues in hydrological modelling: a review, in: Scale issues in hydrological modelling, edited by: Kalma, J. D. and Sivapalan, M., John Wiley \& Sons, 1995.

Boesten, J. J. T. I. and van der Linden, A. M. A.: Modelling the influence of sorption and transformation on pesticide leaching and persistence, J. Environ. Qual., 20, 425-435, 1991.

Brooks, R. H. and Corey, A. T.: Hydraulic properties of porous media, Hydrol. Pap. 3, Colorado State Univ., Fort Collins, Co, 1964.

Brown, J. D., Heuvelink, G. B. M., and Refsgaard, J. C.: An integrated framework for assessing and recording uncertainties about environmental data, Water Sci. Technol., 52(6), 153-160, 2005.

Brown, J. D. and Heuvelink, G. B. M.: Assessing uncertainty propagation through physicaly based models of soil water flow and solute transport, in: Encyclopedia of Hydrological Sciences, edited by: Anderson, M., John Wiley and Sons, Ltd, 2005.

Brown, J. D.: Knowledge, uncertainty and physical geography: towards the development of methodologies for questioning belief,
Transactions of the Institute of British Geographers, 29, 367381, 2004.

Burgess, T. M. and Webster, R.: Optimal interpolation and isarithmic mapping of soil properties: I. The semi-variogram and punctual kriging, J. Soil Sci., 31, 315-331, 1980.

Børgesen, C. D. and Schaap, M. G.: Point and parameter pedotransfer functions for water retention predictions for Danish soils, Geoderma, 127, 154-167, 2005.

Campbell, G. S.: A simple method for determining unsaturated conductivity from moisture retention data, Soil Sci., 117, 311-314, 1974.

Carsel, R. F. and Parrish, R. S.: Developing joint probability distributions of soil water retention characteristics, Water Resour. Res., 24(5), 755-770, 1988.

Christiaens, K. and Feyen, J.: Analysis of uncertainties associated with different methods to determine soil hydraulic properties and their propagation in the distributed hydrological MIKE SHE model, J. Hydrol., 246, 63-81, 2001.

Cook, P. G., Walker, G. R., and Jolly, I. D.: Spatial variability of groundwater recharge in a semiarid region, J. Hydrol., 111, 195212, 1989.

Cressie, N.: Statistics for Spatial Data, New York, John Wiley \& Sons, 1991.

Delcourt, H., Darius, P. L., and De Baerdemaeker, J.: The spatial variability of some aspects of topsoil fertility in two belgian fields, Computers and Electronics in Agriculture, 14, 179-196, 1996.

Delle Site, L.: Factors affecting sorption of organic compounds in natural sorbent/water systems and sorption coefficients for selected pollutants, A review, J. Phys. Chem. Ref. Data, 30(1), 187-439, 2001.

Dubus, I. G. and Brown, C. D.: Sensitivity and first-step uncertainty analyses for the preferential flow model MACRO, J. Environ. Quality, 31, 227-240, 2002.

Dubus, I. G., Brown, C. D., and Beulke, S.: Sources of uncertainty in pesticide fate modelling, Sci. Total Environ., 317, 53$72,2003$.

Efron, B. and Tibshirani, R. J.: An introduction to the bootstrap, Monograph on statistics and applied probability, Chapman and hall, NY, 1993.

Finke, P. A., Wösten, J. H. M., and Janssen, J. H. M.: Effects of uncertainty in major input variables on simulated functional soil behaviour, Hydrol. Processes, 10, 661-669, 1996.

Gardner, W. R.: Some steady state solutions of the unsaturated moisture flow equation with application to evaporation from a watertable, Soil Sci., 85, 228-232, 1958.

Gorres, J. and Gold, A. J.: Incorporating spatial variability into GIS to estimate nitrate leaching at the aquifer scale, J. Environ. Qual., 25(3), 491-498, 1996.

Grathwohl, P. and Halm, D. (Eds.): Integrated Soil and Water Protection: risks from diffuse pollution (SOWA). EU EVK1-CT2002-80022 project, 47 p., http://www.uni-tuebingen.de/sowa/, 2004.

Grathwohl, P. and Halm, D. (Eds.): Guideline for Groundwater Risk Assessment at Contaminated Sites. (GRACOS). EU EVK1-CT1999-00029 project, 65 p., http://www.uni-tuebingen.de/gracos/, 2003.

Green, T. R., Ahuja, L. R., and Benjamin, J. G.: Advances and challenges in predicting agricultural management effects on soil 
hydraulic properties, Geoderma, 116, 3-27, 2003.

Gupta, S. C. and Larson, W. E.: Estimating soil water retention characteristics form particle size distribution, organic matter content, and bulk density, Water Resour. Res., 15, 1633-1635, 1979.

Hamlett, J. M., Horton, R., and Cressie, N. A. C.: Resistant and exploratory techniques for use in semivariogram analysis, Soil Sci. Soc. Am. J., 50, 868-875, 1986.

Hansen, S., Jensen, H. E., Nielsen, N. E., and Svendsen, H.: Simulation of nitrogen dynamics and biomass production in winter wheat using the Danish simulation model Daisy, Fertilizer Research, 27, 245-259, 1991.

Heuvelink, G. B. M. and Webster, R.: Modelling soil variation: past, present, and future, Geoderma, 100, 269-301, 2001.

Heuvelink, G. B. M. and Pebesma, E. J.: Spatial aggregation and soil process modelling, Geoderma, 89, 47-65, 1999.

Heuvelink, G. B. M.: Uncertainty analysis in environmental modelling under a change of spatial scale, Nutrient Cycling in Agroecosystems, 50, 255-264, 1998.

Hinman, W. C. and Bisal, F.: Alterations of soil structure upon freezing and thawing and subsequent drying, Can. J. Soil Sci., 48, 193-197, 1968.

Huang, S. W., Jin, J. Y., Yang, L. P., Bai, Y. L., and Li, C. H.: Spatial variability of nitrate on cabbage and nitrate-N in soil, Soil Sci., 169(9), 640-649, 2004.

Iman, R. L. and Conover, W. J.: A distribution free approach to inducing rank correlations among input variables, Communications in statistics, B11(3), 311-334, 1982.

Iman, R. L. and Shortencarier, M. J.: A FORTRAN 77 Program and Users guide for the generation of Latin Hypercube and random samples for use with computer models, NUREG/CR-3624, U.S. Nuclear Regulatory Commission, Washington D.C., 1984.

Isaaks, E. H. and Srivastava, R. M.: An introduction to applied geostatistics, Oxford University Press, 1989.

Jacques, D., Mouvet, C., Mohanty, B., Vereecken, H., and Feyen, J.: Spatial variability of atrazine sorption parameters and other soil properties in a podzoluvisol, J. Contam. Hydrol., 36, 31-52, 1999.

Jansen, M. J. W.: Prediction error through modelling concepts and uncertainty from basic data, Nutr. Cycl. Agroecosys., 50, $247-$ 253, 1998 .

Jensen, K. H. and Refsgaard, J. C.: Spatial variability of physical parameters and processes in field soils. Part I: Water flow and solute transport in field soils, Nordic Hydrology, 22(5), 275-302, $1991 \mathrm{a}$.

Jensen, K. H. and Refsgaard, J. C.: Spatial variability of physical parameters and processes in field soils. Part II: Water flow at field scale, Nordic Hydrology, 22(5), 303-326, 1991 b.

Journel, A. G. and Huijbregts, C. J.: Mining geostatistics, Academic Press, 1978.

Jury, W. A.: Spatial variability of soil properties, 245-269, in: Vadose zone modeling of organic pollutants, edited by: Hern, S. C. and Melancon, S. M., Lewis Publishers, Chelsea, MI, 1986.

Jury, W. A., Russo, D., Sposito, G., and Elabd, H.: The spatial variability of water and solute transport properties in unsaturated soil: I. Analysis of property variation and spatial structure with statistical models, Hilgardia, 55, 1-32, 1987.

Kay, B. D. and Angers, D. A.: Soil Structure, in: Handbook of Soil Science, edited by: Sumner, M. E., CRC Press, 2003.

Klironomos, J. N., Rillig, M. C., and Allen, M. F.: Designing be- lowground field experiments with the help of semi-variance and power analyses, Applied Soil Ecology, 12, 227-238, 1999.

Kristensen, K., Simmelsgaard, S. E., Djurhuus, J., and Olesen, S. E.: Spatial variability of soil physical and chemical parameters, in: Proceedings of the seminar on site specific farming, edited by: Olesen, S. E., SP report, No. 26, 1995.

Leij, F. J., Alves, W. J., van Genuchten, M. Th., and Williams, J. R.: Unsaturated Soil Hydraulic Database, UNSODA 1.0 User's Manual. Report EPA/600/R96/095, U.S. Environmental Protection Agency, Ada, OK 103 p, 1996.

Leij, F. J., Romano, N., Schaap, M. G., Coppola, A., and Palladino, M.: Topographical attributes to predict soil hydraulic properties along a hillslope transect, Water Resour Res., 40(2), W02407, doi:10.1029/2002WR001641, 2004.

McBratney, A. B., Minasny, B., Cattle, S. R., and Vervoort, R. W.: From pedotransfer functions to soil inference systems, Geoderma, 109, 41-73, 2002.

McBratney, A. B. and Pringle, M. J.: Estimating average and proportional variograms of soil properties and their potential use in precision agriculture, Precision Agriculture, 1, 125-152, 1999.

Meyer, P. D., Ye, M., Neuman, S. P., and Cantrell, K. J.: Combined Estimation of Hydrogeologic Conceptual Model and Parameter Uncertainty, NUREG/CR-6843, PNNL-14534, U.S. Nuclear Regulatory Commission, Washington, D.C., 2004.

Meyer, P. D., Rockhold, M. L., and Gee, G. W.: Uncertainty Analysis of infiltration and subsurface flow and transport for SDMP sites, NUREG/CR-6565, U.S. Nuclear Regulatory Commission, 1997.

Meyer, P. D., Gee G. W., Rockhold M. L., and Schaap, M. G.: Characterization of soil hydraulic parameter uncertainty, in: Proceedings of the International Workshop - Characterization and Measurement of the Hydraulic Properties of Unsaturated Porous Media, edited by: van Genuchten, M. Th., Leij, F. J., and Wu, L. J., 1439-1451, University of California, Riverside, 1999.

Meyer, P. D. and Gee, G. W.: Information on hydrologic conceptual models, parameters, uncertainty analysis, and data sources for dose assessments at decommissioning sites, NUREG/CR-6656, U.S. Nuclear Regulatory Commission, Washington, D.C., 1999.

Minasny, B., McBratney, A. B., and Bristow, K. L.: Comparison of different approaches to the development of pedotransfer functions for water-retention curves, Geoderma, 93, 225-253, 1999.

Mohanty, B. P., Ankeny, M. D., Horton, R., and Kanwar, R. S.: Spatial analysis of hydraulic conductivity measured using disc infiltrometers, Water Resour. Res., 30(9), 2489-2498, 1994.

Moore, I. D.: Effects of surface sealing on infiltration, Trans. ASAE, 24(6), 1546-1552, 1981.

Mualem, Y.: Hydraulic conductivity of unsaturated porous media. Generalized microscopic approach, Water Res. Res., 14(2), 325334, 1976.

Mulla, D. J. and McBratney, A. B.: Soil Spatial Variability, in: Handbook of Soil Science, edited by: Sumner, M. E., CRC Press NY, 2000.

Nemes, A., Schaap, M. G., Leij, F. J., and Wösten, J. H. M.: Description of the unsaturated soil hydraulic database UNSODA version 2.0, J. Hydrol., 251, 151-162, 2001.

Neuman, S. P. and Wierenga, P. J.: A comprehensive Strategy of hydrogeologic modelling and uncertainty analysis for nuclear facilities and sites, NUREG/CR-6805, U.S. Nuclear Regulatory Commission, Washington, D.C., 2003. 
Nielsen, D. R. and Wendroth, O.: Spatial and Temporal Statistics. GeoEcology Textbook, Catena Verlag GmbH, Germany, 2003.

Nilsson, B., Højbjerg, A. L., Refsgaard, J. C., and Troldborg, L.: Uncertainty in geological and hydrogeological data, Hydrol. Earth Syst. Sci. Discuss., 3, 2675-2706, 2006, http://www.hydrol-earth-syst-sci-discuss.net/3/2675/2006/.

Onsoy, Y. S., Harter, T., Ginn, T. R., and Horwath, W. R.: Spatial variability and transport of nitrate in a deep alluvial vadose zone, Vadose Zone J., 4, 41-54, 2005.

Pachepsky, Y. A., Rawls, W. J., and Lin, H. S.: Hydropedology and pedotransfer functions, Geoderma, 131(3-4), 308-316, 2006.

Pachepsky, Y. A., Radcliffe, D. E., and Selim, H. M. (Eds.): Scaling methods in soil physics, CRC Press NY, 2003.

Pachepsky, Y. A., Timlin, D., and Varallyay, G.: Artificial neural networks to estimate soil water retention from easily measurable data, Soil Sci. Soc. Am. J., 60, 727-773, 1996.

Quinn, P., Hewett, C. J. M., and Doyle, A.: Scale appropiate modelling: from mechanisms to management, in: Scales in Hydrology Management, edited by: Tchiguirinskaia, I., Bonell, M., and Hubert, P., IAHS Publication, 287, 17-38, 2004.

Rawls, W. J. and Brakensiek, D. L.: Estimation of soil water retention and hydraulic properties, in: Unsaturated flow in hydrologic modelling-Theory and Practice, edited by: Morel-Seytoux, H. J., NATO ASI Series, Vol. 9, Kluwer Academic, Dordrecht, 275300, 1989.

Rawls, W. J. and Brakensiek, D. L.: Prediction of soil water properties for hydrologic modelling, in: Proceeding Symposium Watershed Management in the Eighties, edited by: Jones, E. B. and Ward, T. J., 30 April-1 May, Denver, CO, Am. Soc. Civil Eng., New York, NY, 293-299, 1985.

Rawls, W. J., Brakensiek, D. L., and Saxton, K. E.: Estimation of soil properties. Trans. ASEA, 25, 1316-1320, 1982.

Refsgaard, J. C., van der Sluijs, J. P., Brown, J., and van der Keur, P.: A framework for dealing with uncertainty due to model structure error, Adv. Water Resour., in press, 2006.

Richter, G. M., Beblik, A. J., Schmalstieg, K., and Richter, O.: Ndynamics and nitrate leaching under rotational and continuous set-aside - a case study at the field and catchment scale, Agr. Ecosyst. Environ., 68(1-2), 125-138, 1998.

Romano, N. and Santini, A.: Effectiveness of using pedo-transfer functions to quantify the spatial variability of soil retention characteristics, J. Hydrol., 202 137-157, 1997.

Russo, D. and Bresler, E.: Soil hydraulic properties as stochastic processes: I. An analysis of field spatial variability, Soil Sci. Soc. Am. J., 45(4), 682-687, 1981.

Russo, D.: Determining soil hydraulic properties by parameter estimation: on the selection of a model for the hydraulic properties, Water Resour. Res., 24, 453-459, 1988.

Schaap, M. G., Leij, F. J., and van Genuchten, M. Th.: ROSETTA: a computer program for estimating soil hydraulic parameters, J. Hydrol., 251, 163-176, 2001.

Schaap, M. G., Leij, F. J., and van Genuchten, M. Th.: Neural Network Analysis for Hierarchial Prediction of Soil Hydraulic Properties, Soil Sci. Soc. Am. J., 62, 847-855, 1998.

Schaap, M. G. and Leij, F. J.: Using neural networks to predict soil water retention and soil hydraulic conductivity, Soil and Tillage Res., 47, 37-42, 1998.

Severino, G., Santini, A., and Sommella, A.: Determining the soil hydraulic conductivity by means of a field scale internal drainage, J. Hydrol., 273(15), 234-248, 2003.

Shahandeha, H., Wrighta, A. L., Honsa, F. M., and Lascano, R. J.: Spatial and temporal variation of soil nitrogen parameters related to soil texture and corn yield, Agron J., 97, 772-782, 2005.

Sobieraj, J. A., Elsenbeer, H., and Cameron, G.: Scale dependency in spatial patterns of saturated hydraulic conductivity, Catena, 55, 49-77, 2004.

Soutter, M. and Musy, A.: Coupling 1D Monte-Carlo simulations and geostatistics to assess groundwater vulnerability to pesticide contamination on a regional scale, J. Contam. Hydrol., 32, 25 39, 1998.

Søvik, A. K. and Aagaard, P.: Spatial variability of a solid porous framework with regard to chemical and physical properties, Geoderma, 113, 47-76, 2003.

Van der Sloot, H. A., Comans, R. N. J., Meeussen, J. C. L., and Dijkstra, J. J.: Leaching methods for soil, sludge and treated biowaste, ECN Environmental Risk Assessment (HORIZONTAL). Final report, http://www.ecn.nl/library/horizontal/, 2004.

van Genuchten, M. Th.: A closed form equation for predicting the hydraulic conductivity of unsaturated soils, Soil Sci. Am. J., 44, 892-898, 1980.

van Genuchten, M. Th., Leij, F. J., and Yates, S. R.: The RETC Code for Quantifying the Hydraulic Functions of Unsaturated Soils, Version 1.0. EPA Report 600/2-91/065, U.S. Salinity Laboratory, USDA, ARS, Riverside, California, 1991.

Vauclin, M., Viera, S. R., Vachaud, G., and Nielsen, D. R.: The use of co-kriging with limited field soil observations, Soil Sci. Soc. Am. J., 47, 175-184, 1983.

Vereecken, H., Diels, J., Van Orshoven, J., Feyen, J., and Bouma, J.: Functional evaluation of pedotransfer functions for the estimation of soil hydraulic properties, Soil Sci. Soc. Am. J., 56, 1371-1378, 1992.

Vereecken, H., Maes, J., Feyen, J., and Darius, P.: Estimating the soil moisture characteristics from texture, bulk density and carbon content, Soil Sci., 148, 389-403, 1989.

Vogel, H.-J. and Roth, K.: Moving through scales of flow and transport in soil, J. Hydrol., 272, 95-106, 2003.

Walker, A., Jurado-Exposito, M., Bending, G. D., and Smith, V. J. R.: Spatial variability in the degradation rate of isoproturon in soil, Environ. Pollut., 111, 407-415, 2001.

Wang, W.: Uncertainty analysis of groundwater flow and solute transport in unsaturated-saturated soil: Maricopa Case. PhD dissertation, Univ. of Arizona, Tucson, 2002.

Warrick, A. W., Myers, D. E., and Nielsen, D. R.: Geostatistical methods applied to soil science, 53-82, in: Methods of soil analysis, part I, edited by: Klute, A., 2nd edition, Soil Sci. Soc. of Am., Madison, WI, USA, 1986.

Wauchope, R. D., Yeh, S., Linders, J. B. H. J., Kloskowski, R., Tanaka, K., Rubin, B., Katayama, A., Kordel, W., Gerstl, Z., Lane, M., and Unsworth, J. B.: Pesticide soil sorption parameters: theory, measurement, uses, limitations and reliability, Pest Manag. Sci., 58, 419-445, 2002.

Webb, T. H. and Lilburne, L. R.: Consequences of soil map unit uncertainty on environmental risk assessment, Aust. J. Soil Res., 43(2), 119-126, 2005.

Wilding, L. P.: Spatial variability: its documentation, accomodation and implication to soil surveys, 166-194, in: Soil spatial variabilty, edited by: Nielsen, D. R. and Bouma, J., Pudoc, Wageningen, The Netherlands, 1985. 
Wollenhaupt, N. C., Mulla, D. J., and Gotway Crawford, C. A.: Soil sampling and interpolation techniques for mapping spatial variability of soil properties, 19-53, in: The state of site specific management for agriculture, edited by: Pierce, F. J. and Sadler, E. J., American Society of Agronomy, Madison, WI, USA, 1997.

Wolt, J., Singh, P., Cryer, S., and Lin, J.: Plackett-Burman sensitivity analysis in environmental modeling, Environ. Toxicol. Chem., 21, 1558-1565, 2002.

Worrall, F., Besien, T., and Kolpin, D. W.: Groundwater vulnerability: interactions of chemical and site properties, Sci. Total Environ., 299 131-143, 2002.

Wösten, J. H. M., Pachepksy, Y. A., and Rawls, W. J.: Pedotransfer functions: bridging the gap between available soil data and missing soil hydraulic characteristics, J.Hydrol., 251, 123-150, 2001.
Wösten, J. H. M., Lilly, A., Nemes, A., and Le Bas, C.: Development and use of a database of hydraulic properties of European soils, Geoderma, 90, 169-185, 1999.

Wösten, J. H. M., Finke, P. A., and Jansen, M. J. W.: Comparison of class and continuous pedotransfer functions to generate soil hydraulic characteristics, Geoderma, 66, 227-237, 1995.

Zhu, J. and Mohanty, B. P.: Upscaling of hydraulic properties of heterogeneous soils, in: Scaling methods in soil physics, edited by: Pachepsky, Y., Radcliffe, D. E., and Magdi Selim, H., 97118, CRC Press NY, 2003. 